\title{
TEKNOLOGI DAN PENDAMPINGAN MONITORING PERAIRAN UNTUK BUDIDAYA DI DESA BABAKAN, KABUPATEN PANGANDARAAN
}

\author{
Noir P. Purba, ${ }^{1,2}$ Ibnu Faizal, ${ }^{1,2}$ Dini Setiwati, ${ }^{1}$ dan Putri G. Mulyani ${ }^{1}$ \\ ${ }^{1}$ Marine Research Laboratory (MEAL), Universitas Padjadjaran \\ ${ }^{2}$ Departemen Kelautan, Universitas Padjadjaran \\ E-mail: noir.purba@unpad.ac.id
}

\begin{abstract}
ABSTRAK. Kegiatan pendampingan monitoring perairan ini bertujuan untuk memberikan informasi terkait penyebab kematian ikan di Keramba Jaring Apung (KJA) di desa Babakan, Kabupaten Pangandaraan. Permasalahan yang dihadapi oleh pembudidaya adalah kematian ikan yang sering sekali terjadi. Untuk itu, metode yang dipakai adalah dengan integrasi hasil penelitian, pengamatan lapangan dan pendampingan. Metode pelaksanaan adalah dengan melakukan pengamatan langsung dan pengukuran langsung parameter air seperti kecerahan, DO, suhu, arus, dan salinitas perairan. Selanjutnya interpretasi dilakukan dengan melihat komoditas ikan yang ada sehingga dapat dijelaskan penyebab kematian ikan. Pendampingan ini dilakukan kepada kelompok Karang Taruna pengelola KJA dan mahasiswa KKN (Kuliah Kerja Nyata). Hasil kualitas air menunjukkan bahwa parameter air di KJA tidak lagi mendukung untuk budidaya dikarenakan arus yang lambat, kecerahan yang rendah, suhu yang tinggi. Hasil kegiatan adalah bahwa kelompok budidaya dan mahasiswa mengetahui bagaimana monitoring perairan dan penyebab kematian ikan serta mendapatkan informasi tentang salah satu kegunaan RHEA sebagai alat ukur untuk monitoring kondisi perairan. Dalam hal ini RHEA dapat digunakan untuk monitor perairan.
\end{abstract}

Kata kunci: Pangandaraan; pemantauan; Netcage; RHEA; GERNED

ABSTRACT. The monitoring accompaniment purpose is to give information related to dead fish event in netcage located in Babakan Village, Pangandaran Region which happens frequently. The method using in this monitoring is integrated between field observation and field measurement of water parameters such as clarity, dissolved oxygen, temperature, current, and water salinity. Commodity of fish is interpreted to get an explanation why dead fish in netcage happens. This accompaniment is for youth organization and Community Service Program of Unpad students. The water quality shows the water parameters in netcage area not supported anymore for fish cultivation. Weak current, low clarity, high temperature made this area not suitable. This accompaniment is to educate college student and community how to monitoring water quality and also to get information of RHEA which can be use as water measurement tools for water conditions.

Key words: Pangandaraan; monitoring; Netcage; RHEA; GERNED

\section{PENDAHULUAN}

Perikanan budidaya merupakan salah satu metode yang digunakan untuk memproduksi ikan dalam jumlah besar (Telfer dan Beveridge, 2001; Mohanty et al., 2004). Agar ikan yang dihasilkan mempunyai kualitas yang baik diperlukan monitoring terhadap lingkungan perairan. Monitoring perairan sangat diperlukan agar biota budidaya dapat hidup sesuai dengan kondisi alamiah dan tidak mengganggu perairan (Tavares et al., 2013; Price et al., 2015). Monitoring dibutuhkan karena kondisi perairan tempat ikan dibudidayakan berfluktuasi menurut lokasi, musim, muson, dan faktor lainnya.

Salah satu wilayah yang sedang dikembangkan Keramba Jaring Apung (KJA) yang berada di wilayah Kabupaten Pangandaraan. Pangandaraan mempunyai potensi sebagai daerah budidaya ikan laut seperti kerapu dan kakap. Hal ini diperkuat dengan adanya KJA lepas pantai yang telah diresmikan oleh Menteri Kelautan dan Perikanan RI. KJA juga dapat dikembangkan di wilayah tepi pantai ataupun perairan air payau. Desa Babakan salah satu usaha dari karang taruna adalah KJA dengan jumlah sekitar 16-20 petak yang didalamnya dibudidayakan ikan komersial seperti ikan hias dan ikan kerapu. Namun beberapa tahun terakhir terjadi kematian ikan yang mengakibatkan berkurangnya pendapatan masyarakat.
Berdasarkan keterangan dari pengelola bahwa kematian ikan sejak adanya penutupan muara. Penutupan ini mengakibatkan air tidak dapat masuk dan keluar ke lokasi budidaya, yang mengakibatkan tidak adanya pertukaran atau sirkulasi air di sekitar KJA. Pengelola juga menyatakan bahwa perubahan suhu di wilayah tersebut mengakibatkan ikan tidak dapat beradaptasi dengan baik. Kematian ikan paling banyak disebabkan oleh faktor eksternal seperti oksigen terlarut (DO) (Mohanty et al., 2014), kadar nutrien yang berlebihan, dan tingginya gas beracun (Basavardi et al., 2012; Putri et al., 2016). Ketepatan lokasi adalah satu yang menentukan keberhasilan budidaya. Wilayah Laut dan sekitarnya juga merupakan daerah yang penggunannya melibatkan sektor lain, sehingga pemanfaatan lahan juga harus melihat faktor lainnnya (Fadliani et al., 2015).

Tujuan dari kegiatan ini adalah memberikan informasi berdasarkan fakta lapangan kepada mahasiswa KKN dan juga Karang Taruna sehingga mengetahui bagaimana monitoring kualitas perairan untuk budidaya dan penyebab kematian ikan. Monitoring ini dapat dilakukan dengan mengukur kualitas perairan secara kontinu (Chandanapalli, 2014; Glasgow et al., 2004). Hasil yang diharapkan adalah meningkatnya pengetahuan mengenai budidaya biota. Selain itu, Untuk mengurangi dampakyanglebih besarlagi terhadap budidaya, diperlukan pemberdayaan masyarakat pesisir yang dilakukan secara 
intensif sehingga dapat menjadikan masyarakat sebagai komponen utama penggerak perekonomian.

Berdasarkan hasil wawancara dengan Kepala Desa serta masyrakat dan Karang Taruna belum adanya pengetahuan dari masyarakat budidaya ikan bagaimana cara pemantauan kualitas perairan untuk budidaya. Permasalahan tersebut yang menjadi landasan dari kegiatan ini yaitu memberikan edukasi serta aplikasi dari pemantauan kualitas perairan di kawasan budidaya sebagai langkah utama untuk mengurangi dampak ikan budidaya mati. Pemberdayaan masyarakat pesisir juga perlu dilakukan secara intensif sehingga dapat menjadikan masyarakat sebagai komponen utama penggerak perekonomian.

\section{METODE}

Desa Babakan mempunyai penduduk yang sebagian besar (80\%) adalah nelayan tangkap, namun karang taruna di wilayah tersebut mempunyai KJA. Lokasi budidaya berada pada jalur keluar sungai sehingga mempunyai karakteristik air payau. Terdapat pelabuhan disekitar area KJA serta adanya pembangunan di wilayah selatan.

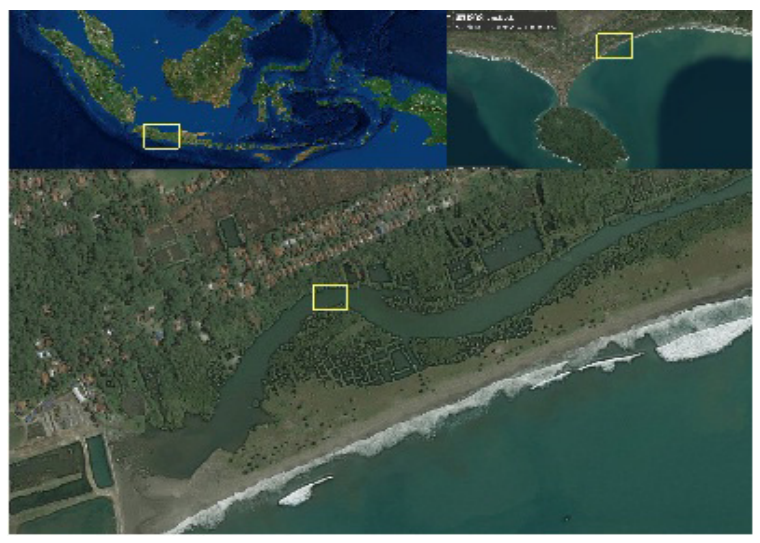

Gambar 1. Lokasi Desa Babakan di arah Timur Pangandaran

Penelitian terkait monitoring perairan sudah dilakukan pada tahun 2017 dan 2018 dengan nama alat GERNED (GPS Drifter Combined) dan RHEA(Drifter GPS Oceanography Coverarge Area) (Purba et al., 2017). Alat ini mengukur data kualitas perairan secara langsung dan dikirimkan ke penerima. Implementasi dari kegunaan alat ini dapat diaplikasikan di perairan air tawar dan air laut.

Metode pelaksanaan kegiatan menjelaskan solusi yang ditawarkan untuk mengatasi permasalahan yang dihadapi pembudidaya, Justifikasi kelompok pembudidaya (karang taruna) dalam menentukan permasalahan prioritas yang harus ditangani, metode pendekatan untuk menyelesaikan permasalahan dan realisasi fakta dan metode yang ditawarkan. Terkait dengan permasalahan yang ada di Desa Babakan, pendampingan ini dilakukan dengan mengindentifikasi masalah yang ada di wilayah kajian. Survei awal dilakukan bersamaan dengan KKN (Kuliah Kerja Nyata) mahasiswa di Desa Babakan pada bulan Juni 2017.
Selanjutnya dilakukan survei awal dan juga tukar informasi serta pemberian saran terhadap solusi dan permasalahan budidaya di wilayah tersebut. Pendampingan juga dilakukan untuk mahasiswa KKN terkait penggunaan alat sehingga nantinya mengetahui kondisi perairan yang cocok untuk budidaya yang dilaksanakan pada bulan Juli 2018.

\section{HASIL DAN PEMBAHASAN}

Pendampingan ini dimulai dari identifikasi permasalahan di sektor perikanan dan kelautan di Desa Babakan, Pangandaraan. Permasalahan ini dilihat oleh mahasiswa KKN (Kuliah Kerja Nyata) yang mengetahui adanya keramba milik karang taruna yang ikannya mati. Kegiatan selanjutnya adalah pengamatan lapangan bersama kelompok. Hasil pengamatan lapangan bersama dengan pengelola KJA dan mahasiswa KKN didapatkan kondisi di sekitar budidaya merupakan perairan semi tertutup dengan di wilayah utara adalah pemukiman masyarakat dan tambak.

Aspek penting dalam pengamatan ini adalah di wilayah selatan yakni adanya pembangunan yang sedang berlangsung untuk wahana wisata dan perguruan tinggi. Kedua pembangunan ini akan berlangsung diperkirakan sampai pada tahun 2020. Pengelola menyatakan bahwa pembangunan ini berdampak kepada budidaya yang dilakukan dikarenakan adanya penutupan saluran air dan juga diprediksikan akan menjadi tekanan bagi keramba. Tutupan lahan adalah mangrove dengan substrat pasir dan lumpur.

Budidaya ini dilakukan sejak tahun 2006 dengan komoditas ikan yang beragam seperti ikan kerapu dan ikan hias. Petak budidaya sekitar 3 x 3 meter dengan konstruksi terbuat dari bambu dan papan. Untuk jarring terbuat dari tali dengan mesh size sekitar 0-1-0.5 cm. Area KJA berada di jalur sempit dan berada di tepi daratan yang berbatasan dengan tambak masyarakat.

Hasil pengamatan lapangan menunjukkan bahwa lokasi budidaya mempunyai kedalaman sekitar 0.5-2 meter dengan jumlah KJA (Keramba Jaring Apung) sekitar 8-12 petak. KJA ini disusun secara berdekatan dengan sistem pengikat tali. Dari pengamatan lapangan didapatkan bahwa ikan-ikan yang mati hampir di semua KJA. Beberapa keramba yang masih dijaga kondisinya dengan melakukan penutupan diatas keramba dengan daun agar sinar matahari tidak langsung masuk ke perairan.

Kondisi perairan hasil pengukuran menunjukkan bahwa beberapa parameter dalam kondisi yang tidak sesuai dengan kehidupan biota budidaya. Dalam hal ini, sesuai dengan hasil diskusi dengan pengelola keramba, bahwa nilai salinitas dan suhu memegang peranan yang penting dalam kematian ikan. Hal ini terbukti dari hasil pengukuran bahwa salinitas mendekati perairan air tawar yang tidak cocok dengan kondisi biota air laut. Hal ini dikarenakan adanya penutupan di daerah muara sehingga air laut tidak dapat masuk ke area keramba. 

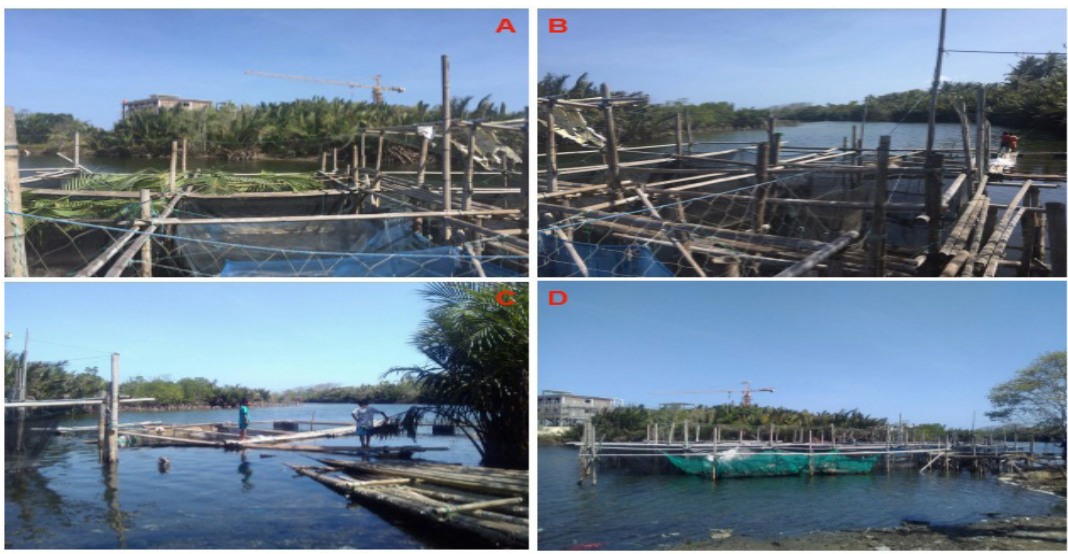

Gambar 2. Profil Budidaya Keramba Jaring Apung: A) Bagian Selatan, B) Bagian Barat, C) Pengelola sedang monitoring, D) KJA di Tepi Daratan
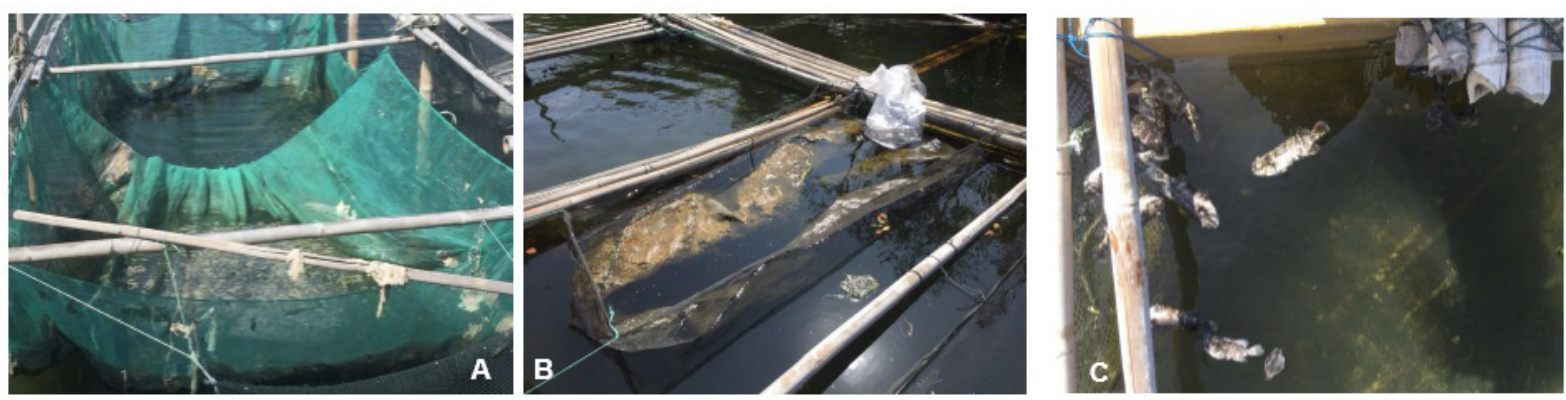

Gambar 3. Kondisi KJA: A). Adanya Buih Limbah, B) Kotoran menempel di jaring, C) Ikan yang telah mati mengapung

Kemudian, nilai suhu yang terlalu tinggi juga mengakibatkan biota menjadi rentan terhadap penyakit. Nilai suhu tinggi ini juga diakibatkan oleh tidak adanya sirkulasi air dan juga kolom air yang tidak terlalu tinggi.

Tabel 1. Pengukuran Kualitas Perairan

\begin{tabular}{cccccc}
\hline \multicolumn{5}{c}{ Nilai pengukuran parameter } \\
\hline $\begin{array}{c}\text { Kecerahan } \\
(\%)\end{array}$ & $\begin{array}{c}\text { Oksigen } \\
\text { terlarut } \\
(\mathrm{mg} / \mathrm{L})\end{array}$ & $\mathbf{p H}$ & $\begin{array}{c}\text { Suhu } \\
\left({ }^{\circ} \mathrm{C}\right)\end{array}$ & $\begin{array}{c}\text { Salinitas } \\
(\mathrm{PSU})\end{array}$ & Substrat \\
\hline $50-70$ & 4 & 8 & 31 & 15 & $\begin{array}{c}\text { Pasir } \\
\text { berlumpur }\end{array}$ \\
\hline
\end{tabular}

Permasalahan lainnya adalah bahwa di KJA masih terdapat banyak limbah yang belum dibersihkan sehingga menjadi zat pencemar bagi ikan yang dibudidayakan. Pada saat survei, ditemukan sekitar 20 ikan sudah dalam keadaan mati, dan menurut keterangan pengelola, bahwa ikan tersebut sudah mati dari hari sebelumnya. Untuk itu, dalam kelayakan budidaya dengan kondisi perairan yang berfluktuasi seperti kasus ini, diperlukan pengukuran secara langsung dan kontinu agar manajemen perairan dapat terkelola dengan baik.

Pendampingan yang dilakukan menunjukkan bahwa nantinya teknologi RHEA dapat meminimalisir kematian ikan yang diakibatkan oleh perubahan lingkungan. Mang Dede sebagai perwakilan kelompok nelayan juga berharap adanya monitoring yang kontinu terhadap lingkungan tempat budidaya. Adapun solusi yang ditawarkan adalah bahwa teknologi dapat membantu tingkat keberhasilan dari pembudidaya dikarenakan dapat langsung dimonitor perubahan lingkungan. Selain itu, aspek penting lainnya dalam tukar informasi adalah konstruksi keramba yang efektif dan tahan lama (Sudrajat et al., 2001) dan pemberian pakan yang efesien (Lamidi dan Asmanelli, 1994).

Kelebihan dari RHEA adalah data parameter perairan bisa didapatkan secara periodik serta dapat diakses secara online. Mekanisme pengiriman dan penerima data adalah komponen yang berada di dalam instrumen yang berfungsi mengirimkan sinyal ke satelit. Data yang diterima satelit kemudian diterima oleh Stasiun yang kemudian masuk kedalam server. Data yang sudah berada di server itu yang dapat kemudian diakses oleh pengguna. Diharapkan, dengan adanya data paramater perairan yang baik, pengelola KJA dapat melakukan langkah cepat tanggap apabila didapatkan anomali pada parameter perairan sehingga kejadian yang tidak diharapkan seperti ikan mati tidak terulang kembali.

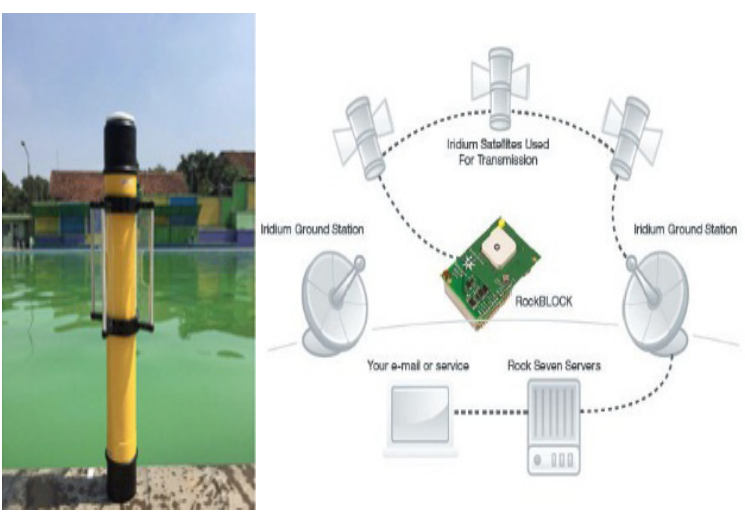

Gambar 5. (kiri) RHEA, (kanan) sistem pengiriman data 
RHEA dapat mengukur kualitas perairan dengan sistem penerimaan satelit. Sensor pada alatakan melakukan pengukuran dan data tersebut ditransfer ke satelit dan dikirim kembali ke server/penerima. Penggunaan satelit sebagai pengirim sinyal dimungkinkan untuk lokasi yang belum terjangkau oleh sinyal telepon.

\section{SIMPULAN}

Kegiatan ini menghasilkan beberapa kesimpulan diantaranya mahasiswa dan pembudidaya mengetahui penyebab kematikan ikan. Hal yang penting lainnya adalah bahwa mahasiswa dapat melakukan pengukuran lapangan dan termotivasi dengan hasil yang didapatkan selama pendampingan.

Kajian ini merupakan Hibah Internal UNPAD (HIU) tahun 2018 yang terintegrasi dengan penelitian dan KKN mahasiswa. Kami mengucapkan terima kasih kepada mahasiswa KKN UNPAD yang telah melakukan survei awal. Kemudian kepada karang taruna pembudidaya (Mang Dede) yang telah bersedia dalam tukar informasi mengenai budidaya serta masyarakat desa Babakan.

\section{UCAPAN TERIMAKASIH}

Kajian ini merupakan Hibah Internal UNPAD (HIU) tahun 2018 yang terintegrasi dengan penelitian dan KKN mahasiswa. Kami mengucapkan terima kasih kepada mahasiswa/i KKN UNPAD yang telah melakukan survei awal. Kemudian kepada karang taruna pembudidaya (Mang Dede) yang telah bersedia dalam tukar informasi mengenai budidaya serta masyarakat desa Babakan.

\section{DAFTAR PUSTAKA}

Basavaraddi, S.B., Kousar, H., \& Puttaiah, E.T. (2012). Dissolved oxygen concentration - a remarkable indicator of ground water pollution in and around Tiptur town, Tumkur District, Karnataka, India, Bull. Env., Pharm. \& Life Sci, 1, (3), 48-54.

Chandanapalli, S.B, Reddy S.E, \& Lakshmi, R.D (2014) Design and Deployment of Aqua Monitoring System Using Wireless Sensor Networks and IAR-Kick. J Aquac Res Development 5, (7), 1-10. doi:10.4172/2155-9546.1000283

Fadliani, S.M., \& Sofyan, D.K. 2015. Usaha Meningkatkan Pendapatan Nelayan Dengan menggunakan Keramba Jaring Apung Pada
Budidaya Kerapu. Malikussaleh Industrial Engineering Journal, 4,(1), 24-29.

Glasgow, H.B., \& Burkholder, J.A \& Reed, M. (2004) Real-time remote monitoring of water quality: are view of current applications, and advancements in sensor, telemetry and computing technologies. $J$ Exp Mar Biol Ecol 300: 409-448.

Tavares, L.H., Millan, R.N. \& Amaral, A.A. (2013). Influence of management on the water quality and sediment in tropical fish farm, J. Water Res. Protec., 5, pp. 495-501.

Lamidi \& Asmanelli, (1994). Pengaruh Dosis Pakan terhadap Pertumbuhan Ikan Lemak. Jurnal Penelitian Budidaya Pantai. 10, (5), 51 - 60.

Mohanty, R.K., Kumar, A. Mishra, A., Panda, D.K., \& Patil, K.U. (2014). Water Budgeting Management: Enhancing Aquacultural Water Productivity, Odisha, India: Directorate of Water Management, Indian Council of Agricult, (Research Bulletin , no.63)

Price, C., Black, K.D., Hargrave, B.T. \& Morris, J.A. (2015). Marine cage culture and the environment: effects on water quality and primary production. Aquaculture Environment Interactions. 6, 151174.

Purba, N.P., Harahap, S.A., Prihadi, D.J., Faizal, I., Mulyani, P.G., Fitriadi, C.A. \& Sitio, J.T. (2017). Pengembangan Instrumen Lagrangian Gps Drifter Combined (Gerned) Untuk Observasi Laut Development Of Lagrangian Instrument, 109-116.

Putri M.R.A., Hartati, S.T. \& Satria, F. 2016. Kematian Massal Ikan Dan Sebaran Parameter Kualitas Air Di Teluk Jakarta. Jurnal Bawal, 8, (2), 77-90.

Sudrajat, A., Heruwati, E.S., Poernomo, A., Rukyani, A., Widodo, J. \& Danakusumah, E. (2001). Teknologi Budidaya Laut dan Pengembangan Sea Farming di Indonesia. Departemen Kelautan dan Perikanan bekerja sama dengan Japan International Cooperation Agency.

Telfer T.C., \& Beveridge M.C.M. (2001). Monitoring environmental effects of marine fish aquaculture. In: UriarteA.(ed.), Basurco B. (ed.). Environmental impact assessment of Mediterranean aquaculture farms. Zaragoza: CIHEAM, p. 75-83 (Cahiers Options Méditerranéennes; n. 55) 